\title{
Recall of simultaneously and successively presented information'
}

PETER L. DERKS AND LAIDLER FREEMAN ${ }^{2}$

THE COLLEGE OF WILLIAM AND MARY

In order to examine the reported similarity in error distribution for recall of successively and simultaneously presented material, the two conditions were compared under total and partial report procedures. However, in this study, omission errors were predominately at the front of the list for successive presentation and to the right for simultaneous presentation with both report procedures. Further investigation of successive presentation total report showed mislocation errors shifted toward the rear of the list relative to omission errors. These results lend some support to descriptions of memory which include a "reception" stage and an "organization" stage. The similarity in error distributions for successive and simultaneous presentations results in part from similar organizational strategies.

Feigenbaum \& Simon (1963) have suggested that an important variable in the relative difficulty of recall of items in a list is the order in which Ss process these items. In general, a finite process time is required so that the items must be organized from anchor points with the first item in the list used as the main base. Thus, items near the beginning of a list are recalled better. Harcum (1966) has used a similar description to call attention to the similarity between serial position errors in serial learning and errors in the report of linear stimuli presented briefly in a tachistoscope. Buschke (1963) has reported a "missing scan" procedure which requires $\mathrm{Ss}$ in a free recall task to report only the item of a finite set of items which was omitted in the presentation. He found that this procedure resulted in "greater memory span" and a greater proportion of errors in the first half of the list.

The present study extended the missing scan technique to the simultaneous presentation of material. The purpose was two-fold: (1) to test the generality of parallel between the acquisition of serial material and the report of simultaneously presented information and (2) to compare the effect of organization for total recall with partial report in the two types of presentation. This comparison is important in the possible distinction between a short term retention with minimized organization requirements for retrieval and a longer term organization for total recall and eventual acquisition.

Method

Eight graduate and undergraduate volunteers experienced in verbal learning and tachistoscopic perception were tested in all conditions. The conditions were presented in random order to Ss in groups of two and three. The Ss received rewards based on their performance in each condition, fewest errors received $\$ 3.00$, next fewest $\$ 2.00$, and third fewest $\$ 1.00$.

The materials were four sets of 10 lists of $6,8,10$, and 12 letters each. The 40 lists were taken from the first $7,9,11$, or 13 letters of the alphabet, respectively。 The lists were selected to omit each letter approximately the same number of times and randomly ordered with the exclusion of obvious words or initial combinations. The lists were presented in order of increasing length for all conditions.

For simultaneous presentation (SI) the stimulus list was shown on a screen approximately $3.0 \mathrm{~m}$ from the Ss by a Bessler overhead projector. Each letter was $11.5 \mathrm{~cm}$ high with a stroke width of $2.0 \mathrm{~cm}$. In order to prevent the formation of position habits, the location of the stimulus on the sereen was not rigidly controlled. The shutter speed was set at $0.5 \mathrm{sec}$. In the successive presentation (SU) the letters in the lists were read aloud approximately $1 \mathrm{sec}$. apart.

For the total recall procedure (TR) Ss were required to write the entire list on a response sheet which had the serial positions numbered. They were told the nature of the lists and urged to guess. In the missing scan procedure (MS) Ss only reported the missing item. Only omission errors were scored in TR to make it comparable to MS.

Results

Table 1-a gives the mean omission errors for all list lengths for all conditions. Since list length was confounded with order and information of the effect of list length on recall in simultaneous and successive tasks already exists, errors were summed over list length for analysis of variance. SI was the more difficult presentation $(F=107.44, \mathrm{df}=1 / 7, \mathrm{p}<.001)$ and MS resulted in fewer errors for report procedures $(\mathrm{F}=11.10, \mathrm{df}=1 / 7, \mathrm{p}<.05)$.

Also presented in Table 1 are the percent errors in the first half of the list for all conditions, the measure used by Buschke (1963). Again the scores are summed over list length for analysis since the shorter lists contribute relatively few errors. Most errors for SU occurred in the first half of the list while errors for SI were shifted to the second half, especially with total report $(F=87.46, d f=1 / 7, p<.001)$ 。

\section{Replication and Discussion}

The SU-TR error distribution of this study does not replicate Buschke's error distribution since errors occur primarily in the first half of the list. However, Buschke noted that his Ss repeated the list from beginning to end. Since the serial position curves of the pres- 
Table 1. Mean Errors (Percent Errors in First Half see text for description of conditions

\begin{tabular}{lcrrrr} 
& \multicolumn{5}{c}{$\begin{array}{c}\text { List Length } \\
\text { o. Experimental }\end{array}$} \\
\hline SU-TR & 6 & 8 & 10 & 12 & $\Sigma$ \\
SU-MS & $1.25(30)$ & $1.75(57)$ & $5.50(75)$ & $7.75(60)$ & $16.25(63.1)$ \\
SI-TR & $1.25(50)$ & $3.12(64)$ & $5.12(76)$ & $4.12(73)$ & $13.25(69.7)$ \\
SI-MS & $4.75(05)$ & $8.50(20)$ & $9.75(29)$ & $11.25(23)$ & $34.25(21.9)$ \\
& $4.75(47)$ & $6.37(43)$ & $8.62(38)$ & $8.75(46)$ & $28.50(43.0)$ \\
& \multicolumn{5}{c}{ b. Replication } \\
SU-FTR(OM) & $1.64(44)$ & $7.64(58)$ & $14.45(64)$ & $20.36(67)$ & $44.09(63.7)$ \\
SU-FTR(MS) & $5.73(38)$ & $14.36(47)$ & $27.91(53)$ & $37.55(54)$ & $85.55(51.8)$ \\
SU-OTR(OM) & $1.75(62)$ & $9.25(42)$ & $20.92(44)$ & $29.58(52)$ & $61.50(48.4)$ \\
SU-OTR(MS) & $4.33(35)$ & $14.25(43)$ & $35.50(43)$ & $43.33(41)$ & $97.25(41.4)$ \\
\hline
\end{tabular}

ent study looked more like curves usually reported for free recall, the Ss in the SU-TR condition may have reported the items by free rather than ordered recall. To test this possibility and to determine the extent to which the sophisticated Ss in this study applied a missing scan strategy prior to total report, two replication groups were tested. The SR-TR condition was replicated with 11 naive Ss free to report in any order (SU-FTR), and a second group of 12 naive Ss was tested with additional instructions to write the list in order (SU-OTR). To check possible order effects for the letters, the lists from the original experiment were used in the replication, but were read in reverse order.

Also examined in the replications were the relations between the omission errors (OM) related to missing scan and the mislocation or confusion errors (MS) more closely related to total recall. MS errors were defined as total errors minus OM errors. If OM errors are a function of stimulus information lost and MS errors are caused by insufficient organization of the remaining material, the MS errors should occur to the rear of the list relative to OM errors.

Of the 23 naive Ss tested, only two noticed that one of the set of letters used to generate the list was omitted on each trial. These Ss utilized this knowledge only after they had recalled as much of the list as they could.
All Ss in the SU-FTR replication used a free recall system and wrote the last, the first, and then the middle items of the list. For this replication, shown in Table 1b, 63.71 percent of OM errors occurred in the first half of the list compared with 63.08 percent for the original study. For MS errors, 51.75 percent occurred in the first half. The difference between $O M$ and MS error proportion is significant by a Wilcoxon Test ( $\mathrm{T}=7, \mathrm{df}=11, \mathrm{p}=.02$ ).

Table 1b also gives the data for the SU-OTR group. With order instructions, 48.4 percent of the OM errors occurred in the first half of the list. The two replication groups differ with respect to percent OM errors in the first half of the lists by a Mann-Whitney $U$ test $(U=10, d f=11 / 12, p<.001)$. Also the MS errors for the SU-OTR group occurred further to the rear with 41.4 percent in the first half $(T=14, d f=12, p=.05)$.

These results are consistent with a concept of a perceptual storage system where information is retained as some function of recency and an organizational system in which the information is processed from an anchor point. However, the two systems have not been completely distinguished in this study. In any case, these data are further evidence that the parallel in error distribution of simultaneous and successive presentations apparently derives from the organizational process.

\section{References}

Buschke, H. Retention in immediate memory estimated without retrieval. Science, 1963, 140, 56-57.

Feigenbaum, E. A., \& Simon, H. A. Brief notes on the EPAM theory of verbal learning. In C. N. Cofer \& Barbara S. Musgrave (Eds.), Verbal behavior and learning. New York: McGraw-Hill, 1963. Pp. 333-335.

Harcum, E. R. Mnemonic organization as a determinant of errorgradients in visual pattern perception. Percept. mot. Skills, 1966 , in press.

\section{Notes}

1. This research was supported by PHS Research Grant MH 0888901 from the National Institutes of Health. We thank E. Rae Harcum for his valuable suggestions at all stages of the investigation and V. V. McKenna for pertinent criticisms of our conclusions. Heidi Pixton assisted in data tabulation.

2. Now at the State University of Iowa. 